Proceedings

\title{
Is There a Wild Animal Welfare Emergency Facilitated by Negative Linguistic Framing in Wildlife Population Control Studies? ${ }^{\dagger}$
}

\author{
Emma F. Randall * and Nieky van Veggel
}

Citation: Randall, E.F. Is There a Wild Animal Welfare Emergency Facilitated by Negative Linguistic Framing in Wildlife Population Control Studies? Proceedings 2021, 73, 10. https://doi.org/10.3390/ IECA2020-08828

Published: 2 December 2020

Publisher's Note: MDPI stays neutral with regard to jurisdictional claims in published maps and institutional affiliations.

Copyright: (C) 2020 by the authors. Licensee MDPI, Basel, Switzerland. This article is an open access article distributed under the terms and conditions of the Creative Commons Attribution (CC BY) license (http://creativecommons.org/licenses /by/4.0/).
Department of Animal Science, Writtle University College, Chelmsford CM1 3RR, UK; 98277551@writtle.ac.uk

* Correspondence: nieky.vanveggel@writtle.ac.uk; Tel.: +1-07592644476

+ Presented at the 1st International Electronic Conference on Animals - Global Sustainability and Animals: Science, Ethics and Policy, 5-20 December 2020; Available online: https://ieca2020.sciforum.net/.

\begin{abstract}
As the world's human population continues grow in number and mobility, and the impacts of climate change take effect, the opportunities for problematic relationships with nonhuman animals multiply. There are escalating threats to health from wild vectors of zoonotic disease, and so-called "invasive" species have been identified as a significant direct driver of an unprecedented period of global biodiversity loss. This brings a sense of genuine urgency to control problematic wild populations; in the UK alone, it is estimated that 38 million wild mammals and birds are killed as pests. However, the impact of these animals is not always objectively appraised. Control interventions are often ineffective, may be counterproductive and can cause severe suffering. Decisions about when, where and how to control animal populations can be affected by attitudes and philosophical perspectives, influenced by how language is used. A systematic review of wildlife population control studies was carried out to determine whether negative linguistic framing of animals was associated with poor welfare outcomes. Framework analysis of titles, abstracts and keywords was used, and assessments made of the welfare impacts of control methods. This analysis revealed language that framed target populations in terms of War, Threat, Place, Victim, Value, Sentience and Naturalness with a range of associated themes. There was a relationship between negative framing and methods with the most adverse welfare outcomes, but the effect was not consistent. It was clear that there are cultural conventions within the science that were reinforced or challenged depending on many factors including the status of the species and the context of the intervention. More work to explore and challenge cultural conventions in describing targeted animals, and robust reporting of the welfare impacts of control methods are needed to tackle this, often disregarded, animal welfare emergency.
\end{abstract}

Keywords: wildlife population control; wild animal welfare; welfare assessment; linguistic framing; invasive species; pest management; systematic literature review

\section{Introduction}

Associations between humans and wild non-human animals (hereafter animals) have been problematic since pre-history [1]. As the global human population (projected to rise to 11 billion people by 2100 [2]) are increasingly mobile, opportunities for problematic interactions are multiplied. Humans encroach on wild areas and introduce species to novel habitats, and climate change alters the range of some species [3]. The IPBES have identified "invasive" species as a direct driver of biodiversity loss [4]. 


\subsection{Animal Suffering}

Approximately 38 million wild mammals and birds are shot, snared, trapped or poisoned in the UK each year [5]. Some interventions cause severe suffering but the regulation of methods of control is less cognisant of welfare than for animals in other contexts. Methods that would otherwise require sedation or analgesics are routinely used in the control of wild populations and a time to insensibility of up to $300 \mathrm{~s}$ is considered acceptable [6]. Additionally, the "Small Ground Vermin Traps Order 1958" exempts spring traps for rats, mice and moles from quality regulation.

\subsection{Attitudes to Animals}

Human cultures have to manage contradictions in how animals are treated [7]. There are different rules governing the treatment of animals as family (pets) and animals that are a nuisance (pests). Cognitive dissonance has been proposed as a phenomenon that enables the justification of behaviour that does not attune with a person's values [8], and it has been proposed that language and labelling influences attitudes to wild animal species [9].

\subsection{Linguistic Framing}

Linguistic framing uses language to conceptualise a subject as a defined problem, with a particular cause and solution [10]. It works by highlighting aspects of the subject which accentuate its salience and projects a moral judgement [10]. It de-emphasises characteristics that would contradict the intended paradigm [10]. Framing may be used intentionally as a tool of persuasion or may unconsciously reflect cultural bias [11]. Cultural context affects the way a framed concept is received, the effect may be different depending on the receiver's, previous experiences [12]. An "ends justify the means" philosophy can be more palatable when a target species is presented as a sufficient threat to a protected species or environment that is framed as precious and vulnerable [13]. How animals are framed differently according to context is apparent in grey literature [14] but is also in scientific writing [15]. As titles, abstracts and keywords distil the content of papers and have the furthest reach [16], analysis of them could provide insight into whether negative framing is associated with animal suffering.

Systematic reviews have been used to for qualitative research [17] to investigate the influence of metaphor on attitudes [18] and can reveal how discourse frames issues to emphasise a perspective [19].

\section{Materials and Methods}

After a systematic search had been carried out (please see Supplementary Materials S1 and S2) and all relevant texts identified and obtained, abstracts of papers were searched for linguistic themes and descriptive and in vivo codes were recorded [20]. Welfare was rated using the Sharp and Saunders' (2011) model which assigns two scores: (A) rates the overall suffering, by plotting duration against intensity (scores $0-8$ ), and (B) rates the mode of death in terms of time to unconsciousness and level of suffering (A-G) [21].

Discourse analysis using a framework analysis approach was used, this allowed the use of a priori themes but also allowed for an iterative element so new themes that emerged from the texts would not be overlooked [22]. Detailed analysis of titles, abstracts and keywords was carried out using the qualitative data analysis software Atlas.ti [14]. Themes were assigned to framing categories as code groups. Documents were organised by method, and the query tool was used to interrogate the frames and themes for each. A "Full content" report was generated for each frame within each document group; this identified quotations, comments and themes. These themes were examined and identified quotations that represented the prevailing attitudes and positive, negative or neutral tone of the relevant papers. Relationships between method of control, welfare and frames and themes could then be inferred. 
Mupepele et al.'s 2014 quality assessment format [23] (designed for conservation studies) was adapted and used to assess the included papers. This method grades the Level of Evidence (LoE) on a hierarchy from weak to strong. (please see Supplementary Materials S3).

\section{Results}

The literature search retrieved the following numbers of records: Web of Science: 1843 records; EBSCO 430 records; Open Grey: 75 records; DEFRA 385 records; NI Assembly: 70 records. After duplicates were removed and titles, abstracts and finally full text papers were screened, the abstracts of 65 papers were available for analysis. Texts spanned 45 years from 1974 to 2019. The a priori frames were confirmed in the literature: War, Place, Victim, Value, Sentience, Threat and Natural with an additional Sentience frame which proved integral to setting the tone in many of the studies.

\subsection{Poison}

The use of poison resulted in poor welfare outcome and framing was overwhelmingly negative. The theme of "infestation" was amplified by repetition and emphasis on size and seriousness; infestations were "heavy" and "substantial" and populations were "abnormally large". "Rodenticide" "resistance" activated War as an image. Sentience was used for sabotage. Rats "rejected bait" and removed burrow-blocking materials, but also depicted rats' sociability and cognitive sophistication. Additionally, Place themes of colonisation were neutralized by themes of "living in", being "resident", or being "occupants", and domestic images of "home". Mice were objectified; their rebounding populations were simply a "build-up".

\subsection{Live Trap and Despatch (LTD) and Kill Traps}

Welfare outcomes were mixed, dependent on trap inspection regime, handling and trap quality Corvids, caught in Larsen or Ladder traps, likely suffered the most harm. Framing was negative or neutral, with differences between species (corvids neutral, mink negative others mixed). War themes framed traps that were "deployed" and "armed", and intervention as a "campaign", particularly in studies that involved the public in killing. Threat and Place was intensified through repetition, "alien invasive" and "harmful invasive" and "abundance". Pathogenic and competitive grey squirrels were juxtaposed with their native red victims Threat to native reds. War and Threat was alsoemphasised by the means of control, for example, "Magnum 116 bodygrip traps" evoked weaponry.

\subsection{Exclusion}

Welfare was generally good in exclusion interventions. Tone was mixed with examples of positive, neutral and negative framing all represented. War themes ("recruitment", "target"), and Threat ("crop damage") were offset by Value themes ("individuality", "social animals", "welfare"). Sentience revealed "social", "cognitively complex" with "individuals" with the agency to make decisions and as having preferences. Place was either neutral ("home ranges") or negative ("Immigrant"). In contrast there were powerful images of conflict; badgers made "incursions" into forbidden areas and rabbits were "recruited". Exclusion fencing was often "deployed". Negative framing was more apparent; there were more severe welfare impacts.

\subsection{Repellents}

Welfare was generally good. The tone of the papers was neutral, and all frames were represented; Value and Sentience dominated, with numerous themes relating to the animals" subjective experience, of "sensing", "cognitive complexity" and "agency". Sensing was depicted in their discrimination between treated and untreated conditions. Animals were presented as legally protected (Value) and public opinion was important in 
the choice of "benign" control. Badgers were Natural but also a Threat, contextualised as pests that have negative impacts though economic costs and crop damage.

\subsection{Other Methods}

Other methods showed a similarly loose association between the tone of framing and welfare outcomes (Table 1).

Table 1. The relationship between the tone (positive, negative or neutral) and welfare outcomes for wildlife population control studies, showing number of studies (n), study quality and years of publication.

\begin{tabular}{ccccccc}
\hline Method (n) & Negative & Positive & Neutral & Welfare & Quality & Years \\
\hline Poison (14) & $\checkmark$ & & & Poor & Low & $1978-2007$ \\
LTD/kill traps (15) & $\checkmark$ & & $\checkmark$ & Mixed & Mixed & $2000-2017$ \\
Exclusion (9) & $\checkmark$ & $\checkmark$ & $\checkmark$ & Good & Good & $2000-2009$ \\
Repellents (7) & & & $\checkmark$ & Good & Good & $2002-2006$ \\
Deterrents (5) & $\checkmark$ & $\checkmark$ & $\checkmark$ & Good & Good & $2001-2019$ \\
Shooting (4) & $\checkmark$ & $\checkmark$ & $\checkmark$ & Mixed & Mixed & $1974-2018$ \\
Fumigation (2) & & & $\checkmark$ & Poor & Low & $1986-2002$ \\
Habitat modification (5) & $\checkmark$ & $\checkmark$ & & Good & Mixed & $1987-2008$ \\
Translocation (1) & $\checkmark$ & & & Mixed & Good & 1996 \\
Immunocontraception (1) & $\checkmark$ & & & Mixed & Good & 2011 \\
\hline
\end{tabular}

\section{Discussion}

Seven framings: War, Place, Victim, Value, Sentience, Threat and Natural. Those previously reported $[14,24,25]$, but the additional Sentience frame proved integral to setting the tone in many of the studies. Poison studies showed negative framing and had poor welfare outcomes. Most of these studies targeted rats. This may reflect the long-held associations between rats and negative human characteristics; they are commonly objects of phobias and disgust [26], and are used as a metaphor to stigmatise other species, e.g., pigeons are denounced as "rats with wings" [27] and squirrels as "tree rats" [28]. Mixed framing and variation in outcome were found where LTD and kill traps were used. The War on wildlife was epitomized in mink studies which were the majority in this group and were exclusively negatively framed. There was a striking intensity that integrated War, Threat and Place. The "alien", "invasive", "harmful", "diseased" mink and squirrels were juxtaposed with "native" victims that projects were attempting to re-establish. This was evident in studies that involved members of the public in carrying out lethal control [29]. The necessity for exaggeration of Threat could be because the public tend not to favour lethal control even where it is presented as more effective and less costly than other means [30]. Moreover, the public are more likely to approve of lethal interventions when a problem species has been deliberately or negligently introduced by humans, so this communication technique could both encourage public participation and dampen opposition [31]. In contrast, corvids were framed neutrally but control methods had poor welfare outcomes; these birds are traditionally disliked in the UK [32], so there may be less need to justify the welfare harms. Additionally, the control actions for corvids were directed by the authors but carried out by professional gamekeepers for whom the interventions would have been routine.

The inconsistent relationship between framing and welfare may reflect cultural conventions in how animals are perceived. Some species evoke contradictory feelings, for example, badgers are native animals but generate extreme oppositional opinions [14]. Additionally, few wildlife population control operations report the actual welfare impact in their studies and much of the literature regarding welfare is based on older studies, some only based on self-reported effects in humans [33]. 


\section{Conclusions}

There was a relationship between negative framing and poor welfare, but this was complex, particularly as there were cultural influences on how species were represented. Negative framing was most apparent in the poison and LTD and kill traps method group, but even within groups there was variation in tone and emphasis. The loosest connection between framing and welfare was in the management of corvids, which were neutrally framed but subject to high welfare risks. In these studies, authors were detached from the intervention by employing the gamekeepers to carry out the control. The analysis has shown that framing is a complex phenomenon and mere policing of language would likely have little influence on how animals are perceived or improve welfare outcomes. The analysis was hindered by a lack of robust reporting of animal welfare in wildlife population control research, potentially obscuring a large-scale welfare emergency. This could be improved if auditing and reporting of welfare impacts could be implemented in future.

Supplementary Materials: The following are available online at www.mdpi.com/25043900/73/1/9/s1.

Author Contributions: Conceptualization, E.F.R. and N.v.V.; methodology, E.F.R. and N.v.V.; software, E.F.R.; validation, E.F.R. and N.v.V.; formal analysis, E.F.R.; investigation, E.F.R. resources, E.F.R. and N.v.V.; data curation, E.F.R.; writing-original draft preparation, E.F.R.; writing-review and editing, E.F.R. and N.v.V.; visualization, E.F.R.; supervision, N.v.V.; project administration, E.F.R. and N.v.V. All authors have read and agreed to the published version of the manuscript.

Funding: This research received no external funding.

Acknowledgments: The authors are grateful for the help of anonymous reviewers in making this paper better.

Conflicts of Interest: The authors declare no conflict of interest.

\section{References}

1. Macdonald, D.W.; Fenn, M.P.G.; Gelling, M. The Natural History of Rodents: Preadaptations to Pestilence. In Rodent Pests and Their Control; Buckle, A.P., Smith, R.H., Eds.; CAB International: Wallingford, UK, 2015; pp. 1-18.

2. Roser, M. Future Population Growth-Our World in Data. Available online: https://ourworldindata.org/future-populationgrowth (accessed on 16 January 2020).

3. Li, J.; Li, D.; Xue, Y.; Wu, B.; He, X.; Liu, F. Identifying Potential Refugia and Corridors under Climate Change: A Case Study of Endangered Sichuan Golden Monkey (Rhinopithecus Roxellana) in Qinling Mountains, China. Am. J. Primatol. 2018, 80, 1-11, doi:10.1002/ajp.22929.

4. Balvanera, P.; Pfaff, A.; Viña, A.; Frapolli, E.G.; Hussain, S.A.; Merino, L.; Minang, P.A.; Nagabhatla, N. The IPBES Global Assessment on Biodiversity and Ecosystem Services. Chapter 2. Status and Trends; Indirect and Direct Drivers of Change; IBPES Secretariat: Bonn, Germany, 2019.

5. RSPCA. Wildlife. Available online: https://science.rspca.org.uk/sciencegroup/wildlife (accessed on 3 December 2019).

6. Iossa, G.; Soulsbury, C.D.; Harris, S. Mammal Trapping: A Review of Animal Welfare Standards of Killing and Restraining Traps. Anim. Welf. 2007, 16, 335-352.

7. Serpell, J. Killer with a Conscience. In The Company of Animals; Serpell, J., Ed.; Cambridge University Press: Cambridge, UK, 1996; pp. 169-185.

8. Bodenhausen, G.V.; Gawronski, B. Attitude Change. In The Oxford Handbook of Cognitive Psychology; Reisburg, D., Ed.; Oxford University Press: Oxford, UK, 2013; pp. 957-969, doi:10.2307/2576362.

9. Dubois, S.; Fenwick, N.; Ryan, E.A.; Baker, L.; Baker, S.E.; Beausoleil, N.J.; Carter, S.; Cartwright, B.; Costa, F.; Draper, C.; et al. International Consensus Principles for Ethical Wildlife Control. Conserv. Biol. 2017, 31, 753-760, doi:10.1111/cobi.12896.

10. Entman, R.M. Framing: Toward Clarification of A Fractured Paradigm. J. Commun. 1993, 43, 51-58, doi:10.1111/j.14602466.1993.tb01304.x.

11. Lakoff, G. Moral Politics: How Liberals and Conservatives Think, 3rd ed.; University of Chicago Press: Chicago, IL, USA, 2016.

12. Lakoff, G. Why It Matters How We Frame the Environment. Environ. Commun. 2010, 4, 70-81, doi:10.1080/17524030903529749.

13. Vucetich, J.A.; Nelson, M.P. The Infirm Ethical Foundations of Conservation. In Ignoring Nature No More: The Case for Compassionate Conservation; Bekoff, M., Ed.; University of Chicago Press: Chicago, IL, USA, 2013; pp. 9-26. 
14. Cassidy, A. Vermin, Victims and Disease: UK Framings of Badgers In and Beyond the Bovine TB Controversy. Sociol. Ruralis 2012, 52, 192-214, doi:10.1111/j.1467-9523.2012.00562.x.

15. Peretti, J.H. Nativism and Nature: Rethinking Biological Invasions. In Bioinvaders; Johnson, S., Ed.; The White Horse Press: Cambridge, UK, 2010; pp. 28-36.

16. Stotesbury, H. Evaluation in Research Article Abstracts in the Narrative and Hard Sciences. J. Engl. Acad. Purp. 2003, 2, 327-341, doi:10.1016/S1475-1585(03)00049-3.

17. Kannemeyer, R.L. A Systematic Literature Review of Attitudes to Pest Control Methods in New Zealand; Manaaki Whenua Landcare Research: Linconln, NZ, USA, 2017; pp. 1-49.

18. Boeynaems, A.; Burgers, C.; Konijn, E.A.; Steen, G.J. The Effects of Metaphorical Framing on Political Persuasion: A Systematic Literature Review. Metaphor Symb. 2017, 32, 118-134, doi:10.1080/10926488.2017.1297623.

19. Burgers, C.; Brugman, B.C.; Boeynaems, A. Systematic Literature Reviews: Four Applications for Interdisciplinary Research. J. Pragmat. 2019, 145, 102-109, doi:10.1016/j.pragma.2019.04.004.

20. Saldaña, J. The Coding Manual for Qualitative Researchers, 2nd ed.; SAGE Publications Limited: London, UK, 2013; doi:10.1017/CBO9781107415324.004.

21. Sharp, T.; Saunders, G. A Model for Assessing the Relative Humaneness of Pest Animal Control Methods; Department of Agriculture, Fisheries and Forestry: Canberra, Australia, 2011.

22. Himsworth, C.G.; Parsons, K.L.; Jardine, C.; Patrick, D.M. Rats, Cities, People, and Pathogens: A Systematic Review and Narrative Synthesis of Literature Regarding the Ecology of Rat-Associated Zoonoses in Urban Centers. Vector-Borne Zoonotic Dis. 2013, 13, 349-359, doi:10.1089/vbz.2012.1195.

23. Mupepele, A.; Walsh, J.C.; Sutherland, W.J. An Evidence Assessment Tool for Ecosystem Services and Conservation Studies In a Nutshell Human's Life Depends on Nature, Biodiversity and Their Related Ecosystem. Ecol. Appl. 2014, 26, 1295-1301, doi:10.1101/010140.

24. Vitali, C. A Frame-Analytical Perspective on Conflict between People and an Expanding Wolf Canis Lupus Population in Central Italy. Oryx 2014, 48, 575-583, doi:10.1017/S0030605313000276.

25. Runhaar, H.; Runhaar, M.; Vink, H. Reports on Badgers Meles Meles in Dutch Newspapers 1900-2013: Same Animals, Different Framings? Mamm. Rev. 2015, 45, 133-145, doi:10.1111/mam.12040.

26. Sevillano, V.; Fiske, S.T. Animals as Social Objects: Groups, Stereotypes, and Intergroup Threats. Eur. Psychol. 2016, $21,206-217$.

27. Jerolmack, C. How Pigeons Became Rats: The Cultural-Spatial Logic of Problem Animals. Soc. Probl. 2008, 55, 72-94, doi:10.1525/sp.2008.55.1.72.

28. Rantzen, E. Damn These Tree Rats! Available online: https://www.dailymail.co.uk/news/article-390805/Damn-tree-rats.html (accessed on 13 February 2020).

29. Bryce, R.; Oliver, M.K.; Davies, L.; Gray, H.; Urquhart, J.; Lambin, X. Turning Back the Tide of American Mink Invasion at an Unprecedented Scale through Community Participation and Adaptive Management. Biol. Conserv. 2011, 144, 575-583, doi:10.1016/j.biocon.2010.10.013.

30. Lute, M.L.; Attari, S.Z. Public Preferences for Species Conservation: Choosing between Lethal Control, Habitat Protection and No Action. Environ. Conserv. 2017, 44, 139-147, doi:10.1017/S037689291600045X.

31. Martin, A.R.; Lea, V.J. A Mink-Free GB: Perspectives on Eradicating American Mink Neovison Vison from Great Britain and Its Islands. Mamm. Rev. 2020, doi:10.1111/mam.12178.

32. Lovegrove, R. Birds - Individual Species Accounts. In Silent Fields; Lovegrove, R., Ed.; Oxford University Press: Oxford, UK, 2007; pp. 100-185.

33. Mason, G.; Littin, K.E. The Humaneness of Rodent Pest Control; Animal Welfare: Washington, DC, USA, 2003, pp 1-37. 